Tropical Journal of Pharmaceutical Research October 2012; 11 (5): 767-775

(C) Pharmacotherapy Group,

Faculty of Pharmacy, University of Benin

Benin City, 300001 Nigeria

All rights reserved.

Available online at http://www.tjpr.org

Research Article

http://dx.doi.org/10.4314/tjpr.v11i5.10

\title{
Anti-dyslipidemic and Antioxidant Potentials of Methanol Extract of Kalanchoe crenata Whole Plant in Streptozotocin-induced Diabetic Nephropathy in Rats
}

\author{
Foyet Angèle Fondjo ${ }^{1}$, René Kamgang ${ }^{1,2^{*}}$, Jean-Louis Essame Oyono ${ }^{2,3}$ \\ and Jeanne Ngongang Yonkeu ${ }^{3}$ \\ ${ }^{1}$ General Endocrinology and Metabolism Systems (GEMS), Laboratory of Animal Physiology, University of Yaoundé \\ I, ${ }^{2}$ Laboratory of Endocrinology and Radioisotopes, Institute of Medical Research and Medicinal Plants Studies, \\ ${ }^{3}$ Faculty of Medicine and Biomedical Sciences, University of Yaoundé I, Cameroon
}

\begin{abstract}
Purpose: The activity of the methanol extract of the whole plant of Kalanchoe crenata (MEKC) was studied for the treatment of diabetes-induced nephropathy in rats.

Methods: Five-day old Wistar rats received a single intraperitoneal streptozotocin injection (90 $\mu \mathrm{g} / \mathrm{kg}$ body weight) to induce diabetes. Kidney disease onset in the rats was observed six weeks after diabetes induction. The rats were orally administered MEKC $(0,50$ and $68 \mathrm{mg} / \mathrm{kg})$ or glibenclamide (5 $\mathrm{mg} / \mathrm{kg}$ ), once daily for 6 weeks. Blood and urine glucose, proteins, lipids, creatinine, malondialdehyde $(M D A)$, superoxide dismutase $(S O D)$ and catalase (CAT) were then evaluated.

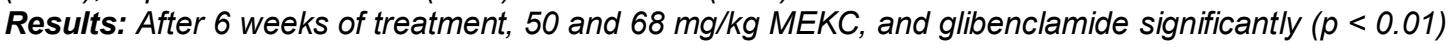
decreased glycaemia (-35, -44 and $-39 \%)$, glycosuria (-38, -47 and $-61 \%)$ and proteinuria $(-82,-80$ and $-72 \%$ ) in diabetes-nephropathic rats. The extract (68 $\mathrm{mg} / \mathrm{kg}$ ) decreased MDA by up to $-44 \%$ (blood), $35 \%$ (liver) and -34 \% (kidney); increased SOD up to $257 \%$ (blood), $116 \%$ (liver) and $118 \%$ (kidney); and CAT by up to $176 \%$ (blood), $78 \%$ (liver) and $96 \%$ (kidney) in the rats, compared with nephropathic control. The extract $(50$ and $68 \mathrm{mg} / \mathrm{kg}$, respectively) lowered $(p<0.01)$ total cholesterolemia $(-24$ and $27 \%)$, blood triglycerides (-55 and $-54 \%)$, blood LDL cholesterol (-48 and $-59 \%)$, but increased blood HDL cholesterol (71 and $58 \%$ ). Overall, atherogenic index was decreased by $31 \%$.

Conclusion: The results indicate that MEKC holds promise for the development of a standardized phytomedicine for diabetes mellitus and kidney disease treatment.
\end{abstract}

Keywords: Diabetes, Dyslipidemia, Antioxidant, Kalanchoe crenata extract, Nephropathy. 


\section{INTRODUCTION}

Diabetic nephropathy is one of the most serious complications of diabetes and the most common cause of end-stage renal failure in the world. Advanced diabetic nephropathy is characterized by specific renal morphological and functional alterations, proteinuria, declined renal function, decreasing creatinine clearance, glomerulosclerosis and interstitial fibrosis [1]. Diabetic kidney disease affects about $25 \%$ of type 1 diabetic patients and $40 \%$ of type 2 diabetic patients [2]. Conventional treatment of diabetes mellitus includes inhibitor of $\alpha$ glycosidase, insulin and oral antihyperglycemic agents [3]. However, alternative therapies are also used, including plant products [4]. Approximately, $80 \%$ of rural African communities still use phytotherapy to control or treat diabetes mellitus [3]. The search for appropriate hypoglycemic agents has focused partly on plants used in traditional medicine since natural products may be better treatments than currently used drugs; furthermore, several plants have been studied and found to possess antidiabetic properties [3].

Kalanchoe crenata (Crassulaceae) is a vegetable widely used in Africa for the treatment of inflammatory diseases [5]. The antihyperglycemic potential of the waterethanol extract of this plant has been demonstrated [6]. Due to the inability of current medications to effectively treat certain diabetic complications such as nephropathy, it is desirable to explore other options inlcuding new drugs from plants. Thus, the present work focused on examining the justification for the traditional use of Kalanchoe crenata in the management of diabetes mellitus and associated kidney diseases.

\section{EXPERIMENTAL}

\section{Plant extract}

The whole plant of Kalanchoe crenata was collected in January and March 2008 from Batie (West Region, Cameroon) and identified by Dr. Onana of the National Herbarium of Yaounde (Cameroon) where a voucher specimen (no. 50103/YA) was kept. The whole plant was cleaned, shade-dried and powdered with a coffee mill (DélonghiBurr milling system). The powder $(2 \mathrm{~kg})$ was macerated in $10 \mathrm{~L}$ of methanol (Analar grade, Normapur, Prolabo) for $72 \mathrm{~h}$ at room temperature. The filtrate concentrated under reduced pressure (i.e., under vacuum) yielded $113.6 \mathrm{~g}(5.68 \%)$ of a dark green residue. This residue was then in $n$-hexane to remove its water-insoluble constituents. The final residue obtained after drying constituted the methanol extract of $K$. crenata (MEKC). The yield of the extract was $41.8 \mathrm{~g}(2.09 \%)$. Prior to administration to the animals, the extract was re-constituted in distilled water and $<1 \mathrm{~mL}$ was given to each animal.

\section{Phytochemical screening test}

Phytochemical analysis of MEKC for its active biological principles was conducted using the methods, chemicals and reagents earlier described [6]: Mayer and Dragendoff's reagents for alkaloids; $\mathrm{FeCl}_{3}$ for tannin; frothing test for saponin; magnesium turning and $\mathrm{HCl}$ for flavonoids; $\mathrm{NaCl}$ and Fehling's solutions for glycoside; diethyl ether, sulphuric acid and anhydride acetic for steroids; ether-chloroform and $\mathrm{NaOH}$ for anthraquinones and $\mathrm{FeCl}_{3}$ and $\mathrm{K}_{3} \mathrm{Fe}(\mathrm{CN})_{6}$ for phenols and polyphenols.

\section{Acute toxicity evaluation}

MEKC was tested for its acute toxicity in mice. Five groups of six mice were orally administered either of the following doses of the extract: $2,4,6,8,10 \mathrm{~g} / \mathrm{kg}$ body weight while the control group received vehicle (water). The animals were continuously 
observed for the first $2 \mathrm{~h}$ for mortality and behavioral abnormalities: lethargy, jerkiness, sensitivity to sound and touch, and respiratory rate. They were then intermittently observed for the next $6 \mathrm{~h}$, and at the 24th and $48^{\text {th }}$ hour following drug administration. The lethal dose for $50 \%$ of the mice $\left(L_{50}\right)$ was determined using Eq 1 [7].

$D L_{50}=X s-d\left(\sum p-1 / 2\right)$

Where $X s=$ lethal dose for $100 \%$ of the mice, $d=$ interval between the doses, $p=$ proportion of death per group, and $\Sigma p=$ sum of death proportions.

\section{Induction of kidney disease}

Male Wistar (5-day old) rats were obtained from the animal house of the Faculty of Science of the University of Yaounde I. They were maintained under natural laboratory conditions (temperature and dark/light cycle) and feeding by their mothers. Their mothers were allowed free access to food and water. Animal housing and experiments were according to the Guidelines of the European Union Directive on Ethical Evaluation of Animal Experiments (CEE Council 86/609) [8] and approved by the Institutional Ethics Committee of the Ministry of the Scientific Research and Innovation of Cameroon.

Diabetes and nephropathy was induced in the 5-day old rats with a single intraperitoneal injection (i.p.) of $90 \mu \mathrm{g} / \mathrm{kg}$ body weight streptozotocin (STZ, Sigma Aldrich, no. SO 130). The STZ (1.0 mL/kg) was freshly prepared in citrate buffer $(0.01 \mathrm{M}, \mathrm{pH} 4.5)$ prior to use. Six weeks after STZ injection, blood glucose and urine protein levels were evaluated. The diabetic rats were characterized by glycaemia $>225 \mathrm{mg} / \mathrm{dL}$, and animals with kidney disease by proteinuria $>$ $3 \mathrm{~g} / \mathrm{L}$.

\section{Effect of the extract on the diseased rats}

In the experiment, 5 normal and 20 diabeticnephropathic rats were used. Nephropathic rats were randomly divided into four groups of 5 animals each. Normal control (NC) and diabetes-nephropathic control (DC) received distilled water; two groups of diabetesnephropathic rats were treated with $50 \mathrm{mg} / \mathrm{kg}$ (DK50) and $68 \mathrm{mg} / \mathrm{kg}$ (DK68), respectively, of the plant extract (MEKC). The diabetesnephropathic reference group (positive control) were treated with glibenclamide (Daonil, Laboratoires Hoechst) $5 \mathrm{mg} / \mathrm{kg}$ (DG5). These drugs were orally administered daily for six weeks using an orogastric tube. The effects of the extract on the diseased rats were evaluated from blood and urinary glucose, and urinary protein levels. After 6 weeks of treatment, all the rats were fasted for $24 \mathrm{~h}$ and spot urine samples were collected to determine urinary glucose and protein levels. The rats were then etheranesthetized, decapitated and blood sample collected in plain and heparined tubes. From the clotted blood at room temperature, serum was collected after centrifugation (3000 rpm, $10 \mathrm{~min}$ ) and used to determine the levels of glucose, total cholesterol, triglycerides, and HDL cholesterol. Blood haemolysate and organ homogenates were prepared to assess thiobarbituric acid-reactive substances (TBARS, i.e., malondialdehyde (MDA), superoxide dismutase (SOD), and catalase (CAT) activities. The serum samples collected for biochemical assays were kept frozen at $-20^{\circ} \mathrm{C}$ until used

\section{Preparation of serum, homogenate and hemolysate samples}

The rat organs (liver and kidney) were removed, weighed and placed immediately in ice-cold buffer $(0.25 \mathrm{M}$ sucrose, $10 \mathrm{mM}$ Tris and $0.3 \mathrm{mM}$ EDTA; $\mathrm{pH}$ 7.4) and washed thoroughly with distilled water to remove blood. The organs were homogenized separately using a Teflon homogenizer. The homogenate was centrifuged (15 min, 15000 rpm), the whole supernatant removed and frozen at $-20^{\circ} \mathrm{C}$ pending subsequent tests.

To prepare hemolysate, $100 \mu \mathrm{L}$ of blood collected in tubes containing heparin was washed three times (by centrifugation at 
$3400 \mathrm{rpm}$ for $5 \mathrm{mim})$ with $2 \mathrm{~mL}$ of $\mathrm{NaCl}(0.9$ $\%)$. After washing, the blood cells were hemolysed in $2 \mathrm{~mL}$ of distilled water. The resulting hemolysate was centrifuged (30 min, $15000 \mathrm{rpm}$ ), and the supernatant was removed and kept frozen at $-20^{\circ} \mathrm{C}$ pending further analysis.

\section{Serum and urine analysis}

Serum parameters were assayed using commercially available kits according to manufacturers' recommendations. Glucose (Bio Direct Laboratories, La Villeneuve France), total cholesterol, triglyceride and HDL cholesterol (c.HDL) kits (Elitect Laboratories, SEPPIMS A. France) were employed. Cholesterol LDL (c.LDL) and atherogenic index $(\mathrm{Al})$ were determined using the Eqs 2 and 3, respectively [9].

$\mathrm{c} . \mathrm{LDL}=\mathrm{T} . \mathrm{C}-\left(\mathrm{c} \cdot \mathrm{HDL}+\frac{\mathrm{TGs}}{\mathrm{n}}\right)$

$A I=T \cdot C-\frac{\mathrm{c} \cdot \mathrm{HDL}}{\mathrm{TC}}$

Proteinuria was quantified by precipitation turbidimetric test of protein in acid trichloroacetic acid (TCA, $12 \%$ ) [10].

\section{Determination of antioxidant activity of the extract}

\section{TBARS (MDA) activity}

To estimate TBARS, $0.4 \mathrm{~mL}$ of homogenate or hemolysate was added to $2 \mathrm{~mL}$ of glacial acetic in a test tube. To this mixture was added $2 \mathrm{~mL}$ of $1 \%$ thiobarbituric acid in $0.5 \mathrm{M}$ $\mathrm{NaOH}$. The loosely stoppered tubes were immersed in boiling water bath for $1 \mathrm{~h}$. The absorbance of the solutions in each tube, cooled under running tap water, was measured spectrophotometrically (Jenway Barloworld Scientific U.K.) at $532 \mathrm{~nm}$ against MDA blank [10].

\section{SOD activity}

To assay SOD activity, $0.2 \mathrm{~mL}$ of homogenate or hemolysate was added to 2.5
$\mathrm{mL}$ of sodium carbonate $(0.05 \mathrm{M}, \mathrm{pH} 10.2)$. The reaction began when $0.3 \mathrm{~mL}$ adrenaline was added. The reaction mixture was stirred vigorously and absorbance measured spectrophotometrically at $480 \mathrm{~nm}$ against blank (sodium carbonate + adrenaline + distilled water). The specific activity of SOD was expressed in units/mg protein. A unit is the quantity of SOD that inhibits $50 \%$ adrenaline oxidation/min [11].

\section{CAT activity}

The assessment of the catalase (CAT) activity was carried out spectrophotometrically based on the decrease in absorbance at $570 \mathrm{~nm}$ against blank (reaction mixture + distilled water) [12]. The reaction mixture contained phosphate buffer (750 $\mu \mathrm{l}, 0.1 \mathrm{M}, \mathrm{pH} 7.5), \mathrm{H}_{2} \mathrm{O}_{2}(200 \mu \mathrm{L}, 50 \mathrm{mM})$ and solution of acetic acid + potassium dichromate $(2 \mathrm{~mL})$. The homogenate or hemolysate $(50 \mu \mathrm{L})$ was added to the mixture. The specific activity of CAT was expressed in $\mu \mathrm{M} \mathrm{H}_{2} \mathrm{O}_{2} / \mathrm{min} / \mathrm{mg}$ protein.

\section{Statistical analysis}

Data are expressed as mean \pm SEM. Biochemical data were analyzed statistically using one-way ANOVA with Graphpad instat 3.6, followed by Dunnett's multiplecomparison test. $P$ values less than 0.05 were considered statistically significant.

\section{RESULTS}

Phytochemical analysis of Kalanchoe crenata methanol extract (MEKC) revealed the presence of different classes of compounds including triterpenes, anthraquinones, phenols, tannins, sterols, phobotanins and polyphenols.

\section{Acute toxicity of extract}

In the acute toxicity test on the extract (MEKC), 4, 6, 8 and $10 \mathrm{~g} / \mathrm{kg}$ doses reduced the sensitiveness of the rats to noise and touch, which also showed jerkiness and 

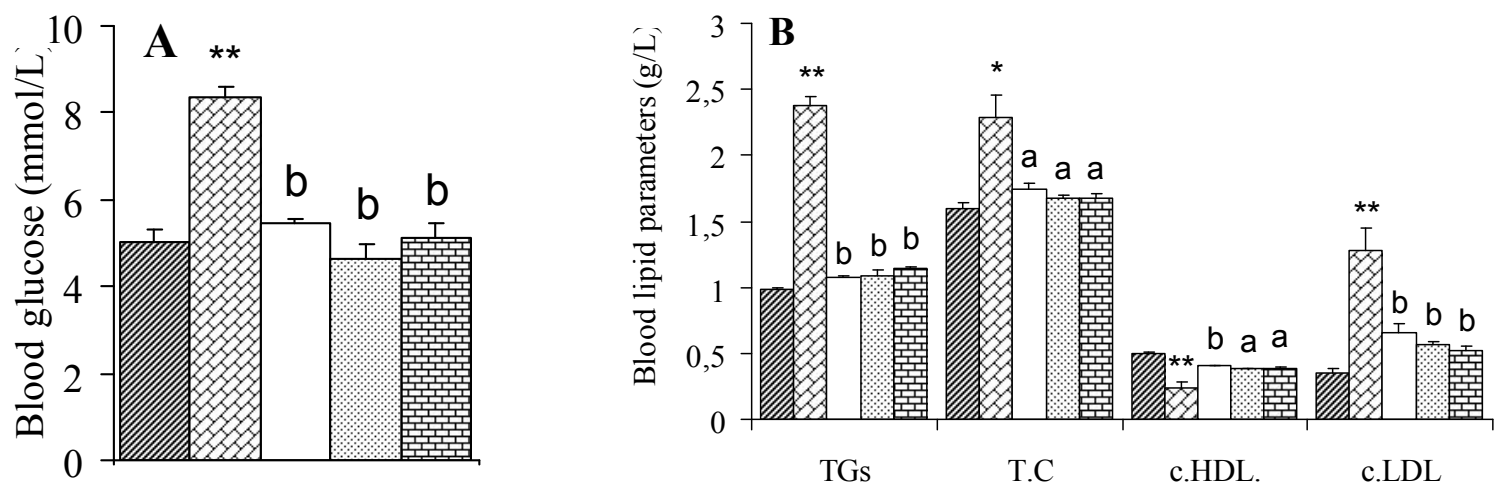

Figure 1: Blood glucose (A) and lipid (B) levels in STZ-induced diabetic nephropathy rats after 6-week daily treatment with $K$ crenata methanol extract $50 \mathrm{mg} / \mathrm{kg}(\square$ DK50) and $68 \mathrm{mg} / \mathrm{kg}$ (㭡DK68), glibenclamide $5 \mathrm{mg} / \mathrm{kg}$ (㯺 DG5). normal control $\left(\mathbb{Z}_{\mathrm{NC}}\right.$ ) and diabetic $\left({ }_{\mathrm{DC}} \mathrm{DC}\right.$ ) control rats. Note: TGs = triglycerides, TC = total cholesterol, c. HDL $=\mathrm{HDL}$ cholesterol, c.LDL $=$ LDL cholesterol. Error bars denote SEM, $\mathrm{n}=5$. Significance difference: ${ }^{*} p<0.05$ and ${ }^{* *} p<0.01$, compared with NC group; ${ }^{\mathrm{a}} p<0.05$ and ${ }^{\mathrm{b}} p<0.01$, compared with DC group.



Figure 2: Atherogenic index of STZ-induced diabetic and nephropathic rats after 6-week daily treatment with $K$ crenata methanol extract 50 $\mathrm{mg} / \mathrm{kg}$ (DK50) and $68 \mathrm{mg} / \mathrm{kg}$ (DK68), glibenclamide $5 \mathrm{mg} / \mathrm{kg}$ (DG5), normal (NC) and diabetic (DC) control rats. Error bars denote SEM, $\mathrm{n}=5 .{ }^{* *} p<0.01$ compared with NC value; ${ }^{\mathrm{b}} p<$ 0.01 ; compared with DC values.

lethargy, and induced soft faeces and $66 \%$ mice death within 30 min of administration. The $10 \mathrm{~g} / \mathrm{kg}$ dose caused $100 \%$ mice death. The lethal dose at $50 \%\left(L_{50}\right)$ was $4.4 \mathrm{~g} / \mathrm{kg}$. There were no gross behavioural changes. Macroscopically, the organs (liver, kidney and heart) did not show any discoloration.

\section{Effect of extract on blood and urine parameters}

In the experimental rats with kidney disease, 12 weeks after onset of diabetes, significant $(p<0.01)$ increase in glycemia $(68 \%)$, total cholesterolemia (43\%), triglyceridemia (138 $\%$ ), blood LDL cholesterol (165\%), and atherogenic index (57\%) was observed (Figs 1 and 2), while HDL cholesterol decreased markedly $(-58 \%)$. Compared with normal control, significant increase glucosuria $(+90$ $\%)$ and proteinuria (+415\%) was observed in diabetes-nephropathic rats (Fig 3).

After 6 weeks of treatment of the nephropathic rats, the extract (50 and 68 $\mathrm{mg} / \mathrm{kg}$ ) and the glibenclamide $(5 \mathrm{mg} / \mathrm{kg})$ significantly $(p<0.01)$ reduced the blood level of the glucose $(-35,-44,-39 \%$, respectively) (Fig $1 \mathrm{~A})$, the triglycerides $(-55$, $54,-52 \%$ respectively), the total cholesterol $(-24,-27,-27 \%$, respectively) and the LDL cholesterol (-48, $-55,-59 \%$ respectively). The cholesterol HDL level was enhanced by $71 \%, 58 \%$ and $58 \%(p<0.01)$ respectively (Fig 1B) and hence decreased the atherogenic index $(-35,-31,-31 \%$ respectively, $p<0.01$ ) (Fig 2). These drugs have decreased $(p<0.01)$ the glucosuria $(-38,-47,-61 \%$ respectively) and the 
proteinuria $(-82,-80,-72 \%$ respectively) (Fig $3)$.

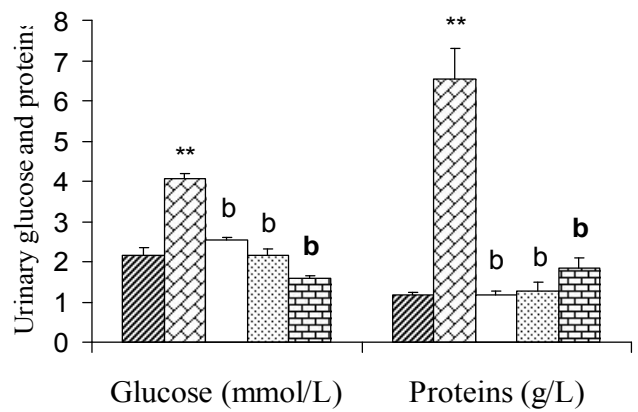

Figure 3: Urinary glucose and protei $n$ levels in STZ-induced diabetic and nephropathic rats after 6 -week daily treatment with $K$ crenata methanol extract $50 \mathrm{mg} / \mathrm{kg}(\square \mathrm{DK} 50)$ and $68 \mathrm{mg} / \mathrm{kg}$ (曽DK68), glibenclamide dose of $5 \mathrm{mg} / \mathrm{kg}$

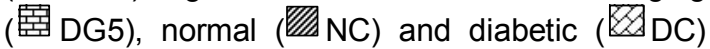
control rats. Error bars denote SEM, $\mathrm{n}=5$. Significance difference: ${ }^{*} p<0.01$ compared with NC value; ${ }^{b} p<0.01$ compared with $D C$ values.

\section{Antioxidant activity of the extract}

Compared with normal rats, there was a significant $(p<0.01)$ increase in TBARS (MDA) concentration in tissue and hemolysate by 63 - $98 \%$. However, significant decrease in CAT levels by between 55 - $70 \%$, and SOD levels by 67 $78 \%$ were observed (Figs 4 and 5). In hemolysate, as in liver and kidney, treatment of the rats with the extract and glibenclamide (reference standard) for 6 weeks lowered $(p$ $<0.01$ ) MDA level by $34-44 \%$, but increased CAT levels by $78-176 \%$, and SOD levels by $116-257 \%$.



Figure 4: Lipid peroxidation, expressed as malondialdehyde (MDA) levels, in rat blood, liver and kidney after 6-week daily treatment with $K$ crenata methanol extract (MEKC). Note: normal $(\mathbb{W} \mathrm{NC}$ and diabetic ( $\mathrm{X} \mathrm{DC}$ ) control rats; diabetic nephropathic rats treated with $50 \mathrm{mg} / \mathrm{kg}$ ( $\square$ DK50) and $68 \mathrm{mg} / \mathrm{kg}$ (图DK68) extract, and with $5 \mathrm{mg} / \mathrm{kg}$ glibenclamide (罥 DG5). Error bars denote SEM, $\mathrm{n}=5 .{ }^{*} p<0.05$ and ${ }^{* *} p<0.01$ compared with NC group; ${ }^{a} p<0.05$ and ${ }^{b} p<0.01$ compared with DC group


Figure 5: Catalase (CAT, A) and superoxide dismutase (SOD, B) activities in diabetes-nephropathic rats after 6 -week daily treatment with $K$ crenata methanol extract dose of $50 \mathrm{mg} / \mathrm{kg}$ ( $\square$ DK50) and $68 \mathrm{mg} / \mathrm{kg}$

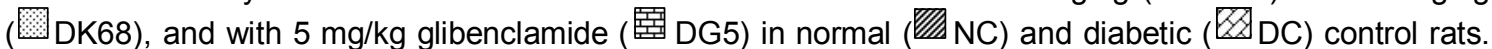
Error bars denote SEM, $\mathrm{n}=5$. ${ }^{* *} p<0.01$ compared with NC group; ${ }^{a} p<0.05$ and ${ }^{\mathrm{b}} p<0.01$ compared with DC group 


\section{DISCUSSION}

This study assessed the effect of $K$. crenata methanolic extract, a plant traditionally used in treatment of diabetes mellitus, on glyceamia, lipidemia, glucosuria, proteinuria and antioxidant activities expressed as SOD, CAT, and MDA in diabetes-induced nephropathy in rats.

In the acute toxicity study, single oral dose of up to $2 \mathrm{~g} / \mathrm{kg}$ of the methanol extract was not lethal to male and female mice. The apparent cause of death of mice in the current study at the doses of $4,6,8$ and $10 \mathrm{~g} / \mathrm{kg}$ might be due to respiratory depression; it is noteworthy that the water-alcohol extract of $K$. crenata did not show lethality in a previous acute toxicity study [6]. The results suggest that MEKC possesses low toxicity since its $L_{50}(5 \mathrm{~g} / \mathrm{kg})$ is 65 and 88 times the test treatment doses [13].

In this study, STZ-induced diabetes resulted in toxic changes in kidney, blood and liver. These changes were indicated by increase in lipid peroxidation and decrease in CAT and SOD activities. SOD and CAT are the two major scavenging enzymes that remove toxic free radicals in vivo. SOD protects tissues against oxygen free radicals by catalyzing the removal of superoxide radical $\left(\mathrm{O}_{2}^{-}\right)$, which damages membrane and cell, while CAT has been shown to be responsible for the detoxification of significant amounts of peroxides. Reduced activities of SOD and CAT activities in the liver and hemolysate have been associated with diabetic nephropathy in rats, leading to a number of deleterious effects due to the accumulation of superoxide radicals and hydrogen peroxide [14].

Increase in lipid peroxidation in diabetic nephropathy may cause peroxidative tissue damage and inflammation [15]. Treatment of the rats with $K$ crenata extract and glibenclamide exhibited antioxidant effect by increasing CAT and SOD activities, and decreasing MDA levels. Restoration of CAT and SOD activities, and MDA level in tissue and hemolysate to normal levels, may be due to the presence of polyphenols, triterpenes and tannins in the extract as they are known to possess antioxidant properties [16]. It is also probable that $K$. crenata brought about its hypoglycemic action through terpenoids that are known to reduce glycemia through many mechanisms which include insulin-like activity, inhibition of gluconeogenesis and glycogenolysis [3].

The increase in urine protein level might have resulted from capillary glomerular hypertrophy or long-term damage that usually leads to increase in glomerular filtration and glomerular urinary protein [17]. Increase in proteinuria could have led to the accumulation of filtered protein in the cytoplasm of the proximal tubular cells, which is associated with interstitial inflammatory reaction and damage of glomerular and kidney tubule [17].

Oxidant stress markers (CAT, SOD and MDA), which are critical factors in the progression of diabetic nephropathy, are increased by inflammatory mechanisms of injury in the kidney $[1,18]$. Both glibenclamide and MEKC markedly decreased the level of proteinuria in the nephropathic rats probably lowering glomerular protein filtration and, in the case of the extract, this may be due to the presence of polyphenols, triterpenes and tannins which are known to have antioxidant properties [16].

Hypercholesterolemia, hypertriglyceridemia and enhanced glomerular lipid synthesis have been implicated in diabetic glomerulosclerosis and known to exercebate kidney diseases [19]. Increased local lipid synthesis appears to be stimulated in diabetes by a number of factors, including increased renal expression of transcription factor, sterol regulatory element binding protein-1 [20]. This endogenous kidney lipid synthesis pathway appears to directly result in enhanced accumulation of intracellular matrix proteins, mesangial expansion and 
glomerulosclerosis [20], suggesting that diabetes induces renal glomerular synthesis of triglycerides and cholesterol, which then promotes glomerulosclerosis. Both MEKCand glibenclamide-treated rats exhibited decrease in total cholesterol, triglycerides, atherogene index and LDL cholesterol levels, and increase in HDL cholesterol level and thus could have a beneficial effect on accumulation of intracellular matrix proteins, glomerulosclerosis and renal expression of the transcription factor, sterol regulatory element binding protein-1 which is associated with hyperglycaemia.

\section{CONCLUSION}

The results show that the methanol extract of $K$. Crenata, at 50 and $68 \mathrm{mg} / \mathrm{kg}$ body weight doses, through its lowering effect on SOD and CAT activities enhanced MDA level, and thus decreased glyceamia, lipidemia, glucosuria and proteinuria. Therefore, the extract possesses anti-diabetic and antinephropathic activities which may explain the traditional use of this plant for management of diabetes and its complications. Hence, the active fraction of the extract could be promising for the development of $a$ standardized phytomedicine for the treatment of diabetes mellitus and kidney disease.

\section{REFERENCES}

1. Abbate $M$, Zoja C, Corna $D$. In progressive nephropathies, overload of tubular cells with filtered proteins translates glomerular inflammation. J Am Soc Nephrol 1998; 9: 1213-1223.

2. Yokoyama H, Okudaira M, Otani T, Sato A, Miura J, Takaike $H$, Yamada $H$, Muto $K$, Uchigata $Y$, Ohashi $Y$, et al. Higher incidence of diabetic nephropathy in type 2 than in type 1 diabetes in early-onset diabetes in Japan. Kidney Int 2000; 58: 302-311.

3. Grover JK, Yadav S, Sats V. Medicinal plants of India anti-diabetic potential. J Ethnopharmacol 2002; 81: 81-100.

4. Diabetes Medicinal Plant Database. (DiaMedBase). in/DMP. 2006. [Cited $2011 \mathrm{Feb}$ 15]. Available from: http://www. progenebio.

5. Dimo T, Fotio LA, Nguelefack TB, Asongalem EA, Kamtchouing $P$. Anti-inflammatory activity of leaf extracts of Kalanchoe Crenata Andr. Ind J pharmacol 2006; 28: 115-119.

6. Kamgang $R$, Youmbi Mboumi $R$, Foyet Fondjo $A$, Fokam Tagne MA, Mengue N'dille GPR, Ngogang Yonkeu J: Antihyperglycaemic potential of the water-extract of Kalanchoe crenata (crassulaceae). J Nat Med 2008; 62: 34-40.

7. Molle J. Limite de tolérance et toxicité de quelques aminosides (Forme $L$ et $D L$ ). Aminopeptidesproteine. Cahier $n^{\circ} 4$, Ed A.E.C., Paris, 1986.

8. Smith JA, Van den Broek FAR, Canto'Martorell J, Hackbarth $H$, Ruksenas O, Zeller W. Federation of European Laboratory Animal Science Associations: FELASA, Working Group on Ethical Evaluation of Animal Experiments). Principles and practice in ethical review of animal experiments across Europe: summary of the report of a FELASA working group on ethical evaluation of animal experiments. Laboratory Animals 2007; 41: 143-160

9. Friedwald WT, Levy RI, Frederickson DS. Estimation of the concentration of low density lipoprotein cholesterol in plasma, without use of preparative ultracentrifuge. Clinical chemical 1972; 8: 499-502.

10. Ohkawa $H$, Ohishi N, Yagi K. Assay of lipid peroxides in animal tissues by thiobarbituric acid reaction. Annal Biochem 1979; 95: 351358.

11. Flohe L, Otting F. Superoxide dismutase assays. Methods Enzymol; 1984; 105: 93-104.

12. Clairbone A. Catalase activity in: RA Greenwald (Ed), CRC Press, Boca Raton, FL; 1985: 283484.

13. Viau C, Tardif R. Toxicologie. In: environnement et santé publique. Fondements et pratiques. 2003: 119-143.

14. Gutteridge JM, Halliwell $B$. Free radicals and antioxidants in the year: a histological book to the future. Ann N Y Acad Sci 2000; 899: 136147.

15. Kurata M, Suzuki M, Agar NS. Antioxidant systems and erythrocyte life span in mammals. Biochemical Physiology 1993; 106: 477-487.

16. Montilla MP, Agil A, Navarro MC, Jimenez MI, Garcia-Granado A, Parra A, Cabo MM. Antioxidant activity of Maslinic acid, a triterpene derivate obtained from olea europaea. Planta Med 2003; 69: 472-474.

17. Harris RC, Neilson EG. Toward a unified theory of renal progression. Ann Rev Med 2006; 57: 365-380.

18. Ohtaket, Kimura $M$, Nishimura. Roles of reactive oxygen species and antioxidant enzymes in murine daunomycin-Induced nephropathy. J Lab Clin Med 1997; 129: 81-88.

19. Proctor G, Jiang $T$, Iwahashi M, Wang Z, Li J, Levi M. Regulation of renal fatty acid and cholesterol metabolism, inflammation, and fibrosis in Akita and Ove 26 mice with type 1 diabetes. Diabetes 2006; 55: 2052-2509. 
Fondjo et al

20. Qian Y, Feldman E, Pennathur S, Kretzler M, Brosius III FC. Mechanism of glomerulo- sclerosis in diabetic nephropathy. Diabetes 2008; 57: 1439-1445. 